\title{
Adrenal activity and metabolic risk during randomized escitalopram or placebo treatment in PCOS
}

\author{
Dorte Glintborg' ${ }^{1}$ Magda Lambaa Altinok', Pernille Ravn², Kurt Bjerregaard Stage³, Kurt Højlund ${ }^{1}$ and \\ Marianne Andersen ${ }^{1}$
}

1Department of Endocrinology and Metabolism, Odense University Hospital, Odense, Denmark

${ }^{2}$ Department of Gynecology and Obstetrics, Odense University Hospital, Odense, Denmark

${ }^{3}$ Department of Psychiatry, Odense University Hospital, Odense, Denmark

Correspondence should be addressed to D Glintborg: dorte.glintborg@rsyd.dk

\begin{abstract}
Background/aims: Polycystic ovary syndrome (PCOS) is associated with insulin resistance, adrenal hyperactivity and decreased mental health. We aimed to investigate the changes in adrenal activity, metabolic status and mental health in PCOS during treatment with escitalopram or placebo.

Methods: Forty-two overweight premenopausal women with PCOS and no clinical depression were randomized to 12-week SSRI (20 mg escitalopram/day, $n=21$ ) or placebo $(n=21)$. Patients underwent clinical examination, fasting blood samples, adrenocorticotroph hormone (ACTH) test, 3-h oral glucose tolerance test (OGTT) and filled in questionnaires regarding mental health and health-related quality of life (HRQoL): WHO Well-Being Index (WHO-5), Major Depression Inventory (MDI), Short Form 36 (SF-36) and PCOS questionnaire.

Results: Included women were aged 31 (6) years (mean (s.D.)) and had body mass index (BMI) $35.8(6.5) \mathrm{kg} / \mathrm{m}^{2}$ and waist $102(12) \mathrm{cm}$. Escitalopram was associated with increased waist (median (quartiles) change $1(0 ; 3) \mathrm{cm}$ ), $P=0.005$ vs change during placebo and increased cortisol levels (cortisol 0, cortisol 60, peak cortisol and area under the curve for cortisol during ACTH test), all $P<0.05$ vs changes during placebo. Escitalopram had no significant effect on measures of insulin sensitivity, insulin secretion, fasting lipids, mental health or HRQoL.

Conclusion: Waist circumference and cortisol levels increased during treatment with escitalopram in women with PCOS and no clinical depression, whereas metabolic risk markers, mental health and HRQol were unchanged.
\end{abstract}

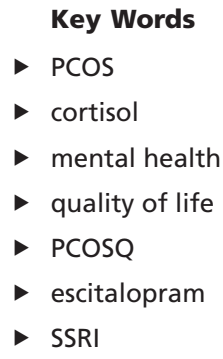

Endocrine Connections (2018) 7, 479-489

\section{Introduction}

Polycystic ovary syndrome (PCOS) is a common endocrine disorder characterized by insulin resistance and hyperandrogenism (1). Central obesity is closely associated with insulin resistance and low-grade inflammation (2) and obesity predicts the development of type 2 diabetes mellitus in PCOS (3). Furthermore, obesity predicted poor

http://www.endocrineconnections.org https://doi.org/10.1530/EC-18-0077

(C) 2018 The authors Published by Bioscientifica Ltd quality of life in women with PCOS (4), and the risk of depression was $2-5$ times increased in PCOS $(5,6)$. PCOS is characterized by increased ovarian and adrenal androgen production (1). Adrenocorticotropic hormone (ACTH)stimulated cortisol and 17-hydroxyprogesterone levels (17OHP) and urinary cortisol secretion were increased in

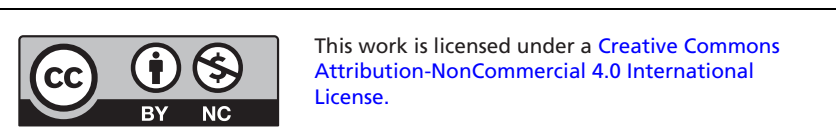


women with PCOS vs controls $(7,8)$, suggesting increased hypothalamic-pituitary-adrenal (HPA) axis activity in PCOS. Increased adrenal activity was also found in patients with major depression and their first-degree relatives compared to healthy controls $(9,10)$. Therefore, decreased quality of life in PCOS could be associated with increased HPA activity (11).

Treatment with specific serotonin reuptake inhibitor (SSRI) is the first choice for depression and 16.3\% Danish women with PCOS had prescriptions of antidepressants (6). The possible effects of SSRI on cortisol secretion, mental health and metabolic risk in PCOS are undetermined (12). Three-month treatment with escitalopram normalized cortisol secretion and improved insulin sensitivity in young healthy men with low birth weight $(<2500 \mathrm{~g})$ (13). Included men were insulin resistant and had high cortisol levels (13). In women, low birth weight increased the risk of elevated adrenal activity and development of PCOS (14). A meta-analysis found improved glycemic control in patients with type 2 diabetes and depression that were treated with antidepressants (15). Improved insulin sensitivity during treatment with SSRI in PCOS could affect the PCOS phenotype and could be associated with more regular menstrual cycles. We are not aware of previous studies testing this hypothesis.

The aim of the present study was to investigate the effect of 12-week escitalopram vs placebo treatment on adrenal activity, mental health, metabolic risk and PCOS phenotype in overweight women with PCOS and no clinical depression.

\section{Materials and methods}

Forty-two women with PCOS were included in a randomized, double-blind, placebo-controlled trial of 12-week medical intervention with SSRI (escitalopram $20 \mathrm{mg}$ ) or placebo. The study was conducted during August 2013 to March 2015 at the Department of Endocrinology, Odense University Hospital. Women were recruited from the outpatient clinic of the Department of Endocrinology and Department of Gynecology at Odense University Hospital and by advertising.

\section{Inclusion criteria}

The study included premenopausal, white women, aged $18-41$ years with PCOS and BMI $>25 \mathrm{~kg} / \mathrm{m}^{2}$ and $<50 \mathrm{~kg} / \mathrm{m}^{2}$. All women fulfilled at least two of the Rotterdam criteria for PCOS: (1) cycle length >35 days or amenorrhea,

$$
\text { http://www.endocrineconnections.org }
$$

(2) total and/or free testosterone above upper reference limit and/or hirsutism (Ferriman-Gallwey score (FG-score) $\geq 8$ ) and (3) polycystic ovaries. Secondary etiologies were excluded as previously described (16). Health-related quality of life (HRQol) is inversely associated with BMI (4) and only overweight and obese women were included in the study. Included women gave informed consent to use barrier control or had an intrauterine device implanted during the study period.

\section{Exclusion criteria}

Clinical depression, evaluated by questions of depressive core symptoms, was an exclusion criterion as treatment with SSRI is the first-line treatment in persons with depression, and we did not consider allocation to placebo treatment possible. Furthermore, exclusion criteria were eating disorder, pregnancy, breastfeeding, epilepsy, diabetes (fasting plasma glucose $\geq 7.0 \mathrm{mmol} / \mathrm{L}$ or $\mathrm{HbA} 1 \mathrm{c}$ $>6.3 \%$ ) or contraindications for escitalopram.

Metformin was paused a minimum of 4 weeks and oral contraceptives 12 weeks prior to evaluation.

\section{Power calculation}

The primary endpoint of the study was change in adrenal activity (evaluated by $60 \mathrm{~min}$ area under the curve (AUC) for ACTH-stimulated cortisol levels) during treatment with escitalopram/placebo. The secondary study outcomes were changes of insulin sensitivity, insulin secretion, fasting lipids, mental health and HRQoL. No previous study investigated the effect of antidepressants on cortisol levels in PCOS and a power calculation could not be performed. Studies on the same number of individuals with depression or first-degree relatives to persons with depression reported significant changes in adrenal activity during antidepressant treatment $(17,18,19)$.

Approvals were obtained from the Ethics committee at the Region of Southern Denmark (registration number: S-20110089) and the Danish Medicine Agency. The study was monitored by the local Good Clinical Practice unit and was registered at www.clinicaltrials.gov: NCT01961180. Consent was obtained from each patient after full explanation of the purpose and nature of all procedures used.

\section{Study protocol}

Patients underwent clinical examination, fasting blood samples, pregnancy test, ACTH test and OGTT and 
answered questionnaires by time of study inclusion and the examination program was repeated after 12-week intervention. Telephone calls were performed at weeks 2 and 6 to check for compliance and side effects. After study inclusion and initial examinations, the patients were randomized 1:1 to escitalopram or placebo. The participants received $10 \mathrm{mg}$ escitalopram during the first week of the study and the dosage was then increased to $20 \mathrm{mg}$ during the remaining study period. The participants down-titrated escitalopram with $10 \mathrm{mg}$ the first week after study termination. Randomization was performed by our hospital pharmacy, which carried out packaging and labeling of escitalopram and placebo.

Physical examination included height, weight, waist circumference, FG score and transvaginal ultrasound ACTH test was performed at 8.00 o'clock in the follicular phase (cycle days 2-8) in women with a cycle length shorter than three months. In women with cycle length longer than three months, ACTH test was performed on a random day. An intravenous bolus of $0.25 \mathrm{mg}$ Synacthen (Novartis Healthcare) was administered and cortisol and $17 \mathrm{OHP}$ levels were measured at 0,30 and $60 \mathrm{~min}$. The maximum cortisol and 17OHP levels during the test were defined as peak levels. Area under the curve for cortisol and $17 \mathrm{OHP}$ was calculated applying the trapezium rule.

A 3-h (h) OGTT was performed at 8:00 o'clock after overnight fasting on a random day of the menstrual cycle. Insulin, C-peptide and blood glucose (BG) were measured at $0,30,60,90,120$ and $180 \mathrm{~min}$ after oral ingestion of a glucose load containing the equivalent of $75 \mathrm{~g}$ anhydrous glucose dissolved in water.

\section{Questionnaires}

\section{Mental health assessment}

Mental health assessments included the 5-item World Health Organization Well-Being Index (WHO-5), the MDI and UKU (Udvalg for Kliniske Undersøgelser). WHO-5 is a general questionnaire regarding mental health (20) and contains five positively phrased items scored from 0 to 5 with higher scores indicating greater well-being. The summed score is multiplied by 4 to translate to percentage. Scores can be rated to risk: 0-35, high risk of depression; $36-50$, risk of depression and $>50$ no risk of depression (20). MDI is a validated depression inventory for screening and diagnosis of depression since it covers the ICD 10 criteria for depression (21). MDI contains 12 items with a total score range from 0 to 50 and higher scores indicate more severe depression (21). Patients were regarded as responders to medical treatment if
MDI-total scores improved $>50 \%$. UKU is a global rating questionnaire regarding side effects to SSRIs, containing 11 questions with range from zero to three (22).

\section{HRQoL assessment}

HRQoL assessments included Short Form-36 (SF-36) and a disease-specific PCOS questionnaire (PCOSQ). SF-36 contains 36 questions grouped into eight domains: Physical function (PF), physical role limitation (RP), bodily pain (BP), general health $(\mathrm{GH})$, vitality (VT), social function (SF), emotional role function (RE) and mental health (MH) (23). Domains were scored from 0 to 100 with higher scores indicating better functioning and QoL. PCOSQ involved 24 items grouped into five domains: Emotions, body hair, weight, infertility problems and menstrual problems (24). Each item was answered in a seven-point rating scale with higher points indicating better functioning. Each domain value was reported as the mean value from the items involved (24).

\section{Biochemical assays}

Plasma total testosterone was analyzed by liquid chromatography tandem mass spectrometry. Free Androgen Index (FAI) was calculated as (total testosterone/ SHBG) $\times 100$. SHBG was analyzed by a time-resolved flouroimmunoassay using a commercial kit (AutoDelfia, Wallac Oy, Turku, Finland). Intra-assay variation was 5.2\% and inter-assay variation was $7.5 \%$. Cortisol was analyzed by time-resolved flouroimmunoassay using commercial kit (AutoDelfia, Wallac Oy, Turku, Finland). Intra-assay variation was $2.7-3.6 \%$ and inter-assay variation was $0.8-1.9 \%$. 17OHP was analyzed by radioimmunoassay (RIA) using a commercial kit (Coat-A-Count, Diagnostic Products Corporation, Los Angeles). Intra- and interassay variations were $3.5-7.1 \%$ and $5.0-11 \%$, respectively. BG was measured with a Hemocue device (Hemocue, Ängelholm, Sweden), which converted BG concentrations to equivalent plasma glucose concentrations (25). The meter was checked with a control cuvette every day and a hemolysate every 1-2 weeks. Serum C-peptide and serum insulin were analyzed by an electrochemiluminescence immunoassay (ECLIA, Cobas e411, Roche), intra-assay CVs were between 0.8 and $4.6 \%$ and inter-assay CVs were between 1.8 and 5.0\%. Plasma total cholesterol, highdensity lipoprotein (HDL), cholesterol and triglyceride (TG) were analyzed by enzymatic colorimetric reactions (Modular P, Roche), and low-density lipoprotein (LDL) cholesterol was calculated using the Friedewald equation.

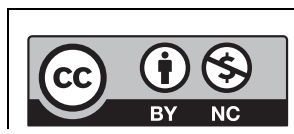

This work is licensed under a Creative Commons Attribution-NonCommercial 4.0 International License. 
Figure 1 presents a flow chart of study participants. Forty-

\section{Insulin resistance}

The homeostatic model assessment insulin resistance index (HOMA-ir) was calculated as (fasting plasma insulin $(\mathrm{U} / \mathrm{L}) \times$ fasting BG $(\mathrm{mmol} / \mathrm{L})) / 22.5$ (26). Using 3-h OGTT data, peripheral insulin sensitivity was calculated as the Matsuda index $(10,000 / \sqrt{ }$ (fasting plasma insulin $(\mathrm{U} / \mathrm{L}) \times$ fasting plasma glucose $(\mathrm{mmol} / \mathrm{L}) \times$ mean plasma insulin $(\mathrm{U} / \mathrm{L}) \times$ mean $\mathrm{BG}(\mathrm{mmol} / \mathrm{L})))(27)$. AUC for insulin, C-peptide and BG during the OGTT (2 and $3 \mathrm{~h}$ ) were calculated applying the trapezium rule.

\section{Insulin secretion and beta cell function}

Basal insulin secretion was assessed by the homeostatic model assessment b-cell function index (HOMA-\%B), calculated as (fasting plasma insulin $(\mathrm{U} / \mathrm{L}) \times 20$ ) $/($ fasting BG (mmol/L) - 3.5) (26). Early glucose-stimulated insulin response was calculated as the insulinogenic index (delta plasma insulin (U/L) (0-30 min)/delta BG (0-30 min) (28). We calculated an OGTT-derived disposition index based on Matsuda $\times$ insulinogenic index.

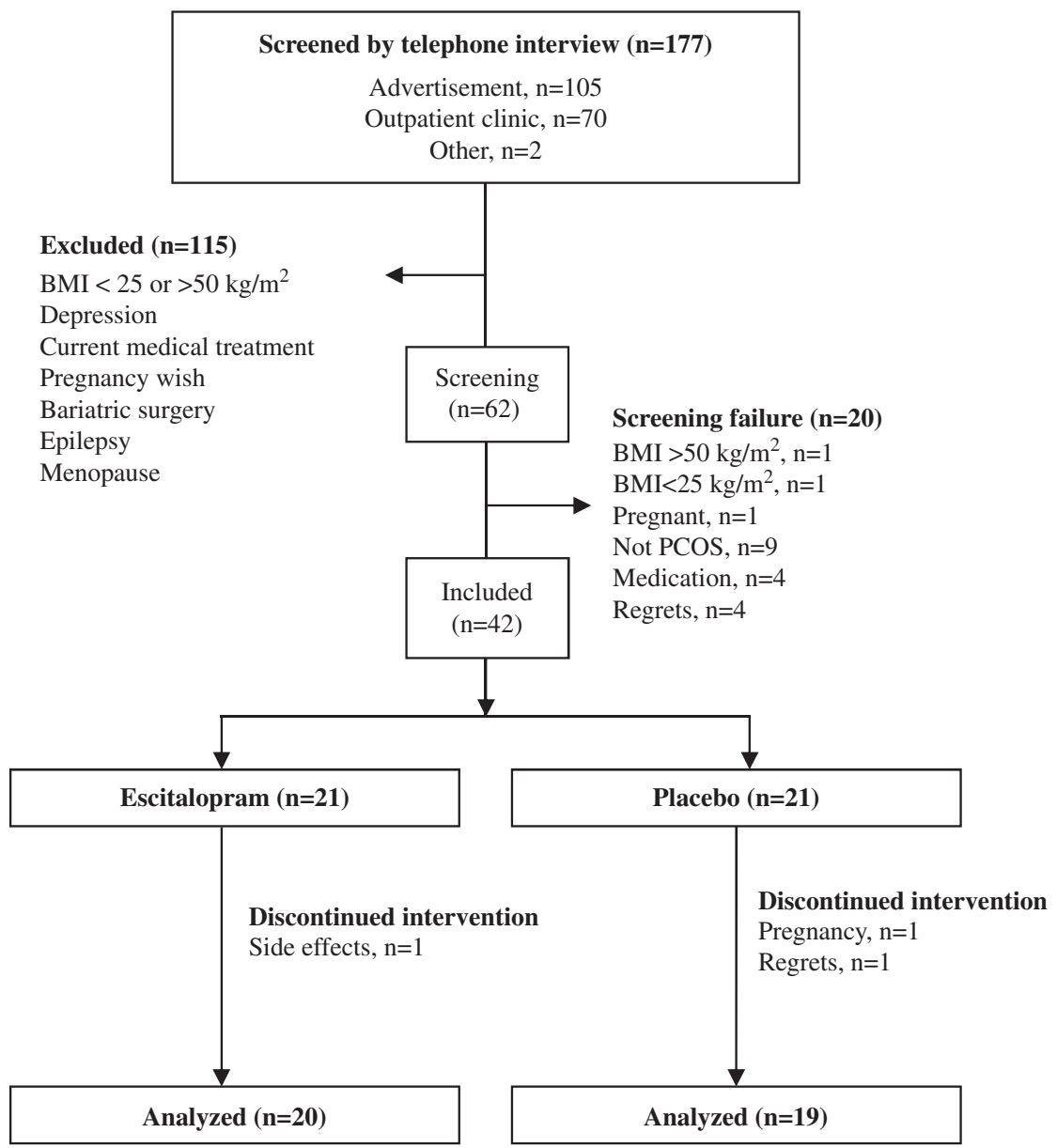

Figure 1

Consort flow chart of included and excluded subjects and study design. two women with PCOS were randomized to escitalopram or placebo and 39 completed study intervention. Twentytwo women (12 citalopram +10 placebo) fulfilled all Rotterdam criteria (phenotype A), 15 (7 citalopram +8 placebo) had phenotype B (hyperandrogenism and oligomenorrhea), two (1 citalopram and 1 placebo) had phenotype $\mathrm{C}$ (hyperandrogenism and $\mathrm{PCO}$ ) and none had phenotype D (oligomenorrhea and PCO).

\section{Statistics}

Continuous variables were described by mean (s.D.) and results from HRQoL assessments were described using medians and quartiles. Pre-treatment differences between patients randomized to escitalopram and placebo were tested using the Mann-Whitney $U$ test. Difference in prevalence between groups was compared by the chisquared test. Changes in outcomes during escitalopram vs placebo were tested by comparing delta $(\Delta)$ values between intervention groups by Mann-Whitney $U$ test. http://www.endocrineconnections.org https://doi.org/10.1530/EC-18-0077
C) 2018 The authors Published by Bioscientifica Ltd 1 
$\Delta$-values were calculated as post-treatment minus pretreatment value of each variable.

Multiple regression analyses were performed to investigate relationships between changes in cortisol levels (dependent variables: $\Delta$-cortisol $0, \Delta$-cortisol 30 , $\Delta$-peak cortisol and $\Delta$-AUC cortisol) and pre-treatment value of the dependent variable (cortisol 0, cortisol 30, peak cortisol or AUC cortisol), medicine group (0 placebo, 1 escitalopram) and $\Delta$-waist (independent variables). Statistics were performed using IBM SPSS Statistics 21. Values of $P<0.05$ were considered significant.

\section{Results}

\section{Clinical and biochemical changes during escitalopram and placebo}

Waist circumference and cortisol levels (cortisol 0, cortisol 60 , peak cortisol and AUC cortisol) increased significantly during escitalopram vs placebo. The median change in waist during escitalopram vs placebo was $1(0 ; 3)$ $\mathrm{cm}$ vs $-1(-2 ; 0) \mathrm{cm}$, respectively, $P=0.005 . \Delta$-waist $>0 \mathrm{~cm}$ (increasing waist during intervention) was seen in $14 / 20$ women treated with escitalopram and in $4 / 19$ women treated with placebo, $P=0.004 . \Delta$-waist $>2 \mathrm{~cm}$ was seen in 9/20 women treated with escitalopram and in $3 / 19$ women treated with placebo, $P=0.05$. BMI, Ferriman-Gallwey score, menstrual regularity (regular, irregular or amenorrhea) and presence of PCO (yes/no) were unchanged during the treatment period. Lipid status (cholesterol, triglycerides, LDL and HDL) and measures of insulin resistance (HOMA-ir, Matsuda index, AUC insulin and AUC C-peptide) and insulin secretion (HOMA-\%B, insulinogenic index and disposition index) were unchanged during study intervention (Table 1).

\section{Mental health and HRQOL}

Changes in WHO-5, MDI and PCOSQ scores were comparable during escitalopram and placebo. The role physical (RP) domain of SF-36 increased during placebo $(P=0.04)$, whereas the remaining domains of SF-36 were unchanged (Table 2).

Low WHO-5 scores $<50$ were in $n=5$ pre-treatment vs $n=2$ post treatment (escitalopram) and in $n=8$ pretreatment and $n=2$ post treatment (placebo), chi test $P=0.002$. MDI scores consistent with depression were not observed in any patients at pre-treatment or after intervention.

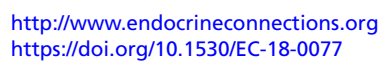

(c) 2018 The authors Published by Bioscientifica Ltd

\section{Multiple regression analyses}

Changes in cortisol during study intervention ( $\Delta$-cortisol $0, \Delta$-cortisol 30, $\Delta$-cortisol 60, $\Delta$-peak cortisol and $\Delta$-AUC cortisol) were predicted by pre-treatment cortisol levels (cortisol 0, cortisol 30, cortisol 60, peak cortisol and AUC cortisol, respectively) in all regression models. Intervention group was an independent predictor of $\Delta$-cortisol 60 and $\Delta$-peak cortisol after correcting for pretreatment cortisol levels and $\Delta$-waist, whereas there was a trend for intervention group as predictor of $\Delta$-AUC cortisol $(P=0.05), \Delta$-cortisol $30(P=0.08)$ and $\Delta$-cortisol $0 \quad(P=0.10)$. Change in waist circumference during intervention ( $\Delta$-waist) did not predict change in cortisol in any of the regression models (Table 3 ).

\section{Discussion}

In the present study, cortisol levels and waist circumference significantly increased during escitalopram vs placebo treatment in overweight premenopausal women with PCOS and no clinical depression, whereas mental health, measures of insulin resistance and insulin secretion, and fasting lipids were unchanged. To our knowledge, this is the first randomized trial regarding HPA axis activity, mental health and metabolic risk during treatment with a SSRI in women with PCOS. Increased cortisol and 17OHP responses during ACTH test is well documented in PCOS (7), and we included measurements of $17 \mathrm{OHP}$ to determine adrenal activity and adrenal androgen production. Our findings of increased cortisol levels during escitalopram treatment contrasted findings from trials in patients with depression and their first-degree relatives (17, 18, 19, 29). However, findings were not uniform as some studies reported unchanged or increased cortisol secretion during SSRI treatment in patients with depression $(30,31)$. We could not confirm results from a recent placebo-controlled study where 3 months treatment with $20 \mathrm{mg}$ escitalopram normalized cortisol levels in healthy men with low birth weight (13). However, the study by Buhl et al. (13) included lean men (mean BMI $22 \mathrm{~kg} / \mathrm{m}^{2}$ ) and adrenal activity was established by 24 -h cortisol patterns (10 cortisol measurements $/ 24 \mathrm{~h}$ ) instead of a stimulation test. High BMI is closely associated with low HRQol in PCOS (4), and we therefore included only overweight and obese women with PCOS in the present study. Furthermore, central and overall obesity is associated with increased cortisol secretion (32) and the pathogenesis of PCOS may be different in obese compared to lean phenotypes (1).

This work is licensed under a Creative Commons Attribution-NonCommercial 4.0 International License. 


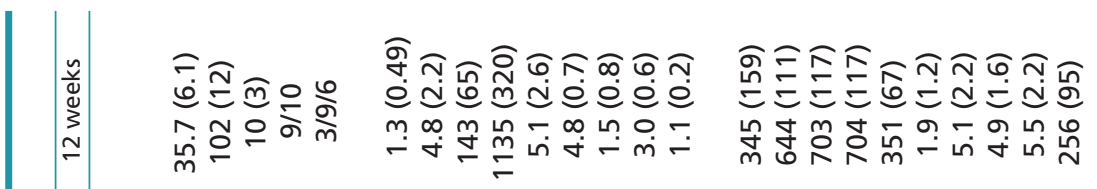

ธิ

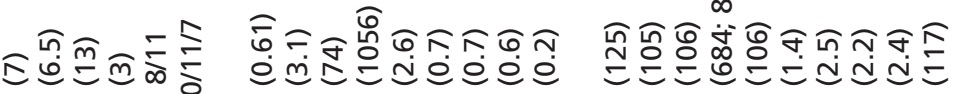

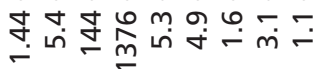

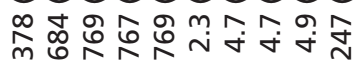

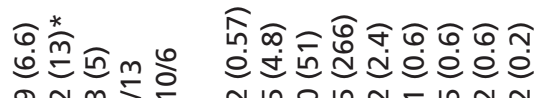

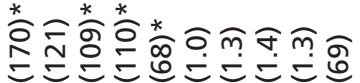

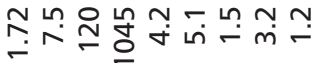

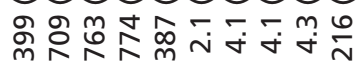

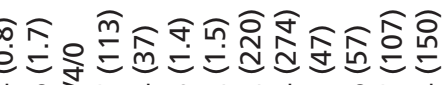

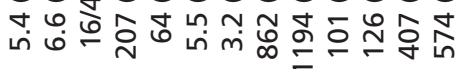

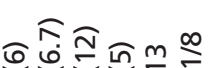
m

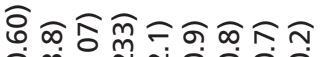

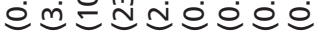

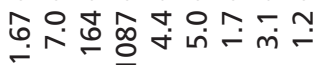

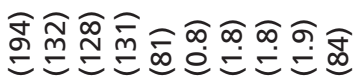

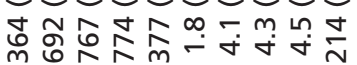

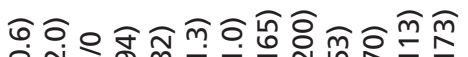
อ di. o

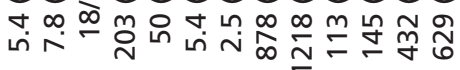

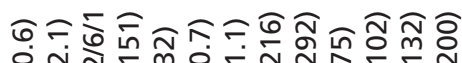
蛨

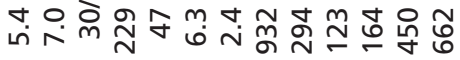


Table 2 Mental health during treatment with escitalopram vs placebo.

\begin{tabular}{l} 
\\
\hline WHO-5 well-being index \\
Major depression inventory \\
SF36 \\
PF: physical function \\
RP: role limitations physical \\
BP: bodily pain \\
GH: general health \\
VT: vitality \\
SF: social function \\
RE: role limitations emotional \\
MH: mental health \\
PCOS-Q \\
PCOSQ emotion \\
PCOSQ body hair \\
PCOSQ weight \\
PCOSQ infertility problems \\
PCOSQ menstrual problems
\end{tabular}

\begin{tabular}{c} 
All $(n=39)$ \\
\hline $64(43 ; 73)$ \\
$14(6 ; 23)$ \\
$90(85 ; 95)$ \\
$100(75 ; 100)$ \\
$90(68 ; 100)$ \\
$60(50 ; 85)$ \\
$55(30 ; 70)$ \\
$100(69 ; 100)$ \\
$100(50 ; 100)$ \\
$76(62 ; 84)$ \\
\\
$4.3(6.6 ; 5.1)$ \\
$2.8(1.6 ; 4.6)$ \\
$2.0(1.2 ; 3.4)$ \\
$5.0(3.5 ; 6.3)$ \\
$4.3(3.2 ; 5.5)$ \\
\hline
\end{tabular}

\begin{tabular}{c} 
Escitaloprat \\
\hline Pre-treatment \\
\hline $64(48 ; 72)$ \\
$13(7 ; 22)$ \\
$90(85 ; 95)$ \\
$100(75 ; 100)$ \\
$90(68 ; 100)$ \\
$60(55 ; 70)$ \\
$55(30 ; 65)$ \\
$100(63 ; 100)$ \\
$100(67 ; 100)$ \\
$76(60 ; 88)$ \\
\\
$4.1(3.4 ; 4.7)$ \\
$2.6(1.6 ; 4.9)$ \\
$2.2(1.2 ; 3.2)$ \\
$4.3(3.1 ; 5.9)$ \\
$4.3(3.3 ; 5.1)$ \\
\hline
\end{tabular}

\begin{tabular}{c}
$(n=20)$ \\
\hline 12 weeks \\
\hline $68(61 ; 76)$ \\
$12(5 ; 17)$ \\
$90(85 ; 95)$ \\
$100(75 ; 100)^{*}$ \\
$90(58 ; 100)$ \\
$65(55 ; 80)$ \\
$60(35 ; 80)$ \\
$100(88 ; 100)$ \\
$67(67 ; 100)$ \\
$80(72 ; 88)$ \\
\\
$5.0(3.7 ; 5.8)$ \\
$2.8(1.5 ; 5.0)$ \\
$2.2(1.4 ; 2.7)$ \\
$6.8(4.1 ; 6.5)$ \\
$5.0(4.3 ; 5.5)$
\end{tabular}

\begin{tabular}{|c|c|}
\hline \multicolumn{2}{|c|}{ Placebo $(n=19)$} \\
\hline Pre-treatment & 12 weeks \\
\hline $56(40 ; 76)$ & $68(52 ; 76)$ \\
\hline $14(5 ; 25)$ & $5(4 ; 11)$ \\
\hline $90(85 ; 95)$ & $93(85 ; 96)$ \\
\hline $75(75 ; 100)$ & $100(94 ; 100)$ \\
\hline $90(75 ; 100)$ & $85(65 ; 100)$ \\
\hline $65(45 ; 85)$ & $70(55 ; 86)$ \\
\hline $50(34 ; 75)$ & $71(54 ; 75)$ \\
\hline $100(69 ; 100)$ & $100(88 ; 100)$ \\
\hline $83(33 ; 100)$ & $100(67 ; 100)$ \\
\hline $72(62 ; 84)$ & $84(68 ; 12)$ \\
\hline $4.3(3.6 ; 5.2)$ & $4.6(4.0 ; 5.8)$ \\
\hline $3.1(2.1 ; 4.6)$ & $3.0(2.4 ; 4.6)$ \\
\hline $1.8(1.2 ; 3.4)$ & $3.0(2.0 ; 3.6)$ \\
\hline $5.4(3.6 ; 6.3)$ & $6.0(3.8 ; 6.8)$ \\
\hline $4.1(3.1 ; 6.0)$ & $4.8(4.3 ; 6.0)$ \\
\hline
\end{tabular}

Data presented as median (quartiles).

${ }^{*} P<0.05 \Delta$-SSRI vs $\Delta$-placebo, Mann-Whitney $U$ test for two samples.

We found significantly increased waist circumference during escitalopram treatment, but changes in waist were not associated with changes in cortisol levels in multiple regression analyses. Instead, pre-treatment cortisol level was the most important predictor of change in cortisol during study intervention. The change in waist during study intervention was highly significant, but it is possible that the change in waist was too small to affect cortisol secretion, and we observed no significant changes in BMI. In accordance with our results, Knorr and coworkers reported no significant correlations between changes in cortisol levels and changes in waist or weight in first-degree relatives to patients with depression treated with escitalopram (33). Furthermore, Buhl and coworkers reported significantly decreased cortisol levels during escitalopram and unchanged body composition established by magnetic resonance imaging (13). Depression is closely associated with the metabolic syndrome, where weight gain may prevail (34), but loss of appetite may also occur (35), and the effect of SSRI treatment on body composition is debated $(35,36)$. Previous studies reported increased $(37,38)$, unchanged $(13,36,39)$ or decreased (40) waist circumference during treatment with SSRI in different study populations,

Table 3 Multiple regression analyses.

\begin{tabular}{|c|c|c|c|c|}
\hline \multirow[b]{2}{*}{ Dependent variables } & \multicolumn{4}{|c|}{ Independent variables } \\
\hline & Pre-treatment cortisol $^{\#}$ & Medicine group & $\Delta$-Waist & $R^{2}$ \\
\hline$\Delta$-Cortisol 0 & $-0.5(0.00) * *$ & $75(0.10)$ & $-5.4(0.48)$ & $0.34(0.002) *$ \\
\hline$\Delta$-Cortisol 30 & $-0.6(0.001) *$ & $68(0.08)$ & $-2.9(0.65)$ & $0.33(0.003) *$ \\
\hline$\Delta$-Cortisol 60 & $-0.3(0.009)$ * & $61(0.04) *$ & $-0.03(0.99)$ & $0.28(0.009) *$ \\
\hline$\Delta$-Peak cortisol & $-0.3(0.005)$ * & $71(0.03)$ * & $-1.5(0.78)$ & $0.30(0.005) *$ \\
\hline \multirow[t]{2}{*}{$\Delta$-AUC cortisol } & $-0.5(0.002) *$ & $4007(0.05)$ & $-1.4(0.78)$ & $0.29(0.006) *$ \\
\hline & Pre-treatment cortisol ${ }^{\#}$ & Medicine group & $\Delta$-BMI & $R^{2}$ \\
\hline$\Delta$-Cortisol 0 & $-0.5(0.001) * *$ & $57(0.18)$ & $11.2(0.55)$ & $0.34(0.002) *$ \\
\hline$\Delta$-Cortisol 30 & $-0.5(0.001) *$ & $55(0.08)$ & $10.4(0.52)$ & $0.33(0.002) *$ \\
\hline$\Delta$-Cortisol 60 & $-0.3(0.01) *$ & $61(0.03)$ * & $-0.83(0.95)$ & $0.28(0.009) *$ \\
\hline$\Delta$-Peak cortisol & $-0.4(0.005) *$ & $68(0.03)$ * & $-1.2(0.92)$ & $0.30(0.005) *$ \\
\hline$\Delta$-AUC cortisol & $-0.4(0.004)$ * & $3394(0.08)$ & $-511(0.78)$ & $0.24(0.006) *$ \\
\hline
\end{tabular}

Predictors of changes in cortisol levels during intervention. Data presented as $\beta$-coefficient ( $P$-value), $* P<0.05, * * P<0.001$. Models regarding predictors of changes in cortisol 0 , cortisol 30, cortisol 60, peak cortisol and AUC cortisol during intervention. Entered independent variables in each regression model: \#pre-treatment value of each individual dependent variable (cortisol 0, cortisol 30, cortisol 60, peak cortisol, or AUC cortisol), medicine group (0 placebo, $1 \mathrm{SSRI}$ ), and change in body composition ( $\Delta$-waist or $\Delta$-BMI).

$$
\begin{array}{lr}
\text { http://www.endocrineconnections.org } & \text { () } 2018 \text { The authors } \\
\text { https://doi.org/10.1530/EC-18-0077 } & \text { Published by Bioscientifica Ltd }
\end{array}
$$


whereas we are not aware of data in PCOS. Previous publications pooled data from males and females (36, $37,38,39,40)$, which could have affected study results. Furthermore, in some papers, the type of SSRI may have affected the study outcome with escitalopram having a smaller (36) or a higher (38) effect on fat mass compared with other SSRIs. Even a small reduction in weight would have significant implications for PCOS phenotype and risk of diabetes and long-term data are needed to determine the effect of escitalopram on waist and body composition in PCOS. Changes in adrenal activity during escitalopram vs placebo were tested by comparing $\Delta$-values between intervention groups. Interestingly, we found that women in the placebo group experienced lowering of cortisol levels during intervention, which could have affected significant findings of the present study. Our results could support that participating in a clinical trial may have a positive effect of adrenal activity and HRQol. Results of clinical trials without a placebo group should be interpreted with caution.

Changes in HRQoL were comparable between escitalopram and placebo in the present study, but the SF-36 domain, RP improved significantly during placebo vs escitalopram treatment. We found comparable changes in mental health (WHO-5 and MDI scores) between escitalopram and placebo, but the presence of low WHO-5 scores decreased significantly during placebo, which supported a positive effect of trial participation. Side effects to SSRI treatment could affect mental health and patients' emotions (41), but UKU was unchanged during study intervention, supporting that side effects did not affect our study outcomes. Women in the present study did not fulfill clinical criteria for depression, and it may be argued that out study population was 'too healthy' at baseline in comparison to studies performed on patients with clinical depression. The results of the present study were, however, in accordance with Knorr et al. (42), where changes in depression scores were similar between escitalopram and placebo in healthy relatives to patients with depression. Buhl did not report HRQol during treatment with escitalopram in healthy males with low birth weight (13), but the authors found no structural changes in the limbic brain morphology during study intervention. A recent meta-analysis on mental health during SSRI therapy found no placebo-controlled trials in patients with depression (43). The meta-analysis concluded that treatment with SSRI improved depression scores in patients with depression, but the clinical effect of improved depression scores was questionable and

http://www.endocrineconnections.org https://doi.org/10.1530/EC-18-0077

() 2018 The authors Published by Bioscientifica Ltd the risk of side effects and serious adverse events during SSRI was increased (43). These results were, however, questioned due to unclear definition of side effects and omission of clinical trials from the meta-analysis (44). Escitalopram treatment is not registered for treatment of patients without clinical depression, and our data support that escitalopram is not effective in treating impaired HRQol in PCOS. More studies are needed regarding the effect of escitalopram in women with PCOS and clinical depression.

Measures of insulin resistance were unchanged during escitalopram in the present study. Escitalopram is an inhibitor of 5-hydroxytryptamine and stimulates serotonergic activity. Increased serotoninergic activity was associated with increased insulin sensitivity (45). In accordance, glycemic control was improved in patients with type 2 diabetes during treatment with SSRI (15) and insulin sensitivity increased in non-diabetic study populations $(13,37,40)$. The median BMI of our study population was $33 \mathrm{~kg} / \mathrm{m}^{2}$ and the participants had high fasting insulin levels, supporting an insulin resistant PCOS phenotype. Our study could be underpowered to detect small changes in insulin sensitivity during escitalopram, but we found no improvement of PCOS characteristics including cycle regularity, which further supported that escitalopram did not improve insulin sensitivity to any clinically relevant extent. Furthermore, we found no changes in lipid levels during escitalopram. Previously, there have been reports on changes in TG in non-PCOS populations during SSRI $(35,36,40,46)$. However, findings were not uniform as some authors reported increased (35, 46), decreased (40) or unchanged (36) TG levels during escitalopram treatment. None of these studies reported data on women alone and various patient populations and types of antidepressants were included in the studies (35, $36,40,46)$. SSRI treatment could stimulate $\alpha_{1}$ receptors in fat tissue and enhance lipolysis (47). In accordance, a microdialysis study showed acute release of glycerol and free fatty acids from the subcutaneous fat tissue during treatment with escitalopram (47). Furthermore, changes in lipid status could be secondary to changes in weight, insulin sensitivity or HPA axis activity. Our finding of unchanged metabolic status during treatment with escitalopram is reassuring given common use of antidepressive treatment in PCOS $(4,6)$.

Strengths and limitations may apply to the present study. The study was randomized, placebo-controlled, double-blinded, and participants were thoroughly evaluated in one single medical center. It was not possible 
to do a power calculation and the present study should therefore be considered a pilot study. Adrenal activity was evaluated by ACTH test performed in the morning, but the study results could have been strengthened by adding 24-h s-cortisol profiles or measurement of urinary cortisol excretion. We used a combination of disease-specific and generic questionnaires to describe HRQoL. Measures of insulin sensitivity were calculated at fasting and by measures derived from 3-h OGTT. The euglycemic-hyperinsulinemic clamp is the golden standard to measure insulin sensitivity, but the present study did not support any clinical relevant changes in glucose tolerance, insulin sensitivity or insulin secretion after escitalopram treatment. Our study design could have been improved by adding measurements of free fatty acids and inflammatory markers such as adiponectin or interleukins.

We included overweight and obese women with PCOS and our study results may not apply in lean women with PCOS. Furthermore, different study results may be found in women with PCOS and major depression.

In conclusion, treatment with escitalopram increased cortisol levels and waist circumference in women with PCOS and no clinical depression, whereas mental health and measures of insulin resistance were unchanged. More studies are needed to determine long-term metabolic and clinical outcomes after SSRI treatment in other PCOS phenotypes and in women with PCOS and depression.

\section{Declaration of interest}

Lundbeck sponsored escitalopram and placebo, but was not involved in economy, planning of project or evaluation of results and writing of the article. The other authors have nothing to declare.

\section{Funding}

Supported by a research grant from the Danish Diabetes Academy funded by the Novo Nordisk Foundation.

\section{Acknowledgements}

The authors thank Anne Mette Hangaard, Susanne Møller Pedersen, Geraldine Rasmussen and Thon Kowall Andersen for excellent technical assistance.

\section{References}

1 Glintborg D. Endocrine and metabolic characteristics in polycystic ovary syndrome. Danish Medical Journal 20164 B5232.

2 Eckel RH, Grundy SM \& Zimmet PZ. The metabolic syndrome. Lancet 20059468 1415-1428. (https://doi.org/10.1016/S01406736(05)66378-7)
3 Conway G, Dewailly D, Diamanti-Kandarakis E, Escobar-Morreale HF, Franks S, Gambineri A, Kelestimur F, Macut D, Micic D, Pasquali R, et al. The polycystic ovary syndrome: a position statement from the European Society of Endocrinology. European Journal of Endocrinology 20144 1-29.

4 Dokras A, Clifton S, Futterweit W \& Wild R. Increased risk for abnormal depression scores in women with polycystic ovary syndrome: a systematic review and meta-analysis. Obstetrics and Gynecology 20111 145-152. (https://doi.org/10.1097/ AOG.0b013e318202b0a4)

5 Cinar N, Kizilarslanoglu MC, Harmanci A, Aksoy DY, Bozdag G, Demir B \& Yildiz BO. Depression, anxiety and cardiometabolic risk in polycystic ovary syndrome. Human Reproduction 201112 3339-3345. (https://doi.org/10.1093/humrep/der338)

6 Glintborg D, Hass RK, Nybo M, Abrahamsen B \& Andersen M. Morbidity and medicine prescriptions in a nationwide Danish population of patients diagnosed with polycystic ovary syndrome. European Journal of Endocrinology 20155 627-638. (https://doi. org/10.1530/EJE-14-1108)

7 Glintborg D, Hermann AP, Brusgaard K, Hangaard J, Hagen C \& Andersen M. Significantly higher adrenocorticotropin-stimulated cortisol and 17-hydroxyprogesterone levels in 337 consecutive, premenopausal, caucasian, hirsute patients compared with healthy controls. Journal of Clinical Endocrinology and Metabolism 20053 1347-1353. (https://doi.org/10.1210/jc.2004-1214)

8 Azziz R, Black V, Hines GA, Fox LM \& Boots LR. Adrenal androgen excess in the polycystic ovary syndrome: sensitivity and responsivity of the hypothalamic-pituitary-adrenal axis. Journal of Clinical Endocrinology and Metabolism 19987 2317-2323.

9 Vreeburg SA, Hoogendijk WJ, van PJ, Derijk RH, Verhagen JC, van DR, Smit JH, Zitman FG \& Penninx BW. Major depressive disorder and hypothalamic-pituitary-adrenal axis activity: results from a large cohort study. Archives of General Psychiatry 20096 617-626. (https://doi.org/10.1001/archgenpsychiatry.2009.50)

10 Modell S, Lauer CJ, Schreiber W, Huber J, Krieg JC \& Holsboer F. Hormonal response pattern in the combined DEX-CRH test is stable over time in subjects at high familial risk for affective disorders. Neuropsychopharmacology 19984 253-262. (https://doi.org/10.1016/ S0893-133X(97)00144-9)

11 Benson S, Arck PC, Tan S, Hahn S, Mann K, Rifaie N, Janssen OE, Schedlowski M \& Elsenbruch S. Disturbed stress responses in women with polycystic ovary syndrome. Psychoneuroendocrinology 20095 727-735. (https://doi.org/10.1016/j.psyneuen.2008.12.001)

12 Zhuang J, Wang X, Xu L, Wu T \& Kang D. Antidepressants for polycystic ovary syndrome. Cochrane Database of Systematic Reviews 20135 CD008575. (https://doi.org/10.1002/14651858.CD008575. pub2)

13 Buhl CS, Stodkilde-Jorgensen H, Videbech P, Vaag A, Moller N, Lund S \& Buhl ES. Escitalopram ameliorates hypercortisolemia and insulin resistance in low birth weight men with limbic brain alterations. Journal of Clinical Endocrinology and Metabolism 2018103 115-124. (https://doi.org/10.1210/jc.2017-01438)

14 Ibanez L, Potau N, Francois I \& de Zegher F. Precocious pubarche, hyperinsulinism, and ovarian hyperandrogenism in girls: relation to reduced fetal growth. Journal of Clinical Endocrinology and Metabolism 199810 3558-3562. (https://doi.org/10.1210/jcem.83.10.5205)

15 Baumeister H, Hutter N \& Bengel J. Psychological and pharmacological interventions for depression in patients with diabetes mellitus and depression. Cochrane Database of Systematic Reviews 201212 CD008381. (https://doi.org/10.1002/14651858. CD008381.pub2)

16 Glintborg D, Henriksen JE, Andersen M, Hagen C, Hangaard J, Rasmussen PE, Schousboe K \& Hermann AP. Prevalence of endocrine diseases and abnormal glucose tolerance tests in 340 Caucasian premenopausal women with hirsutism as the referral diagnosis.

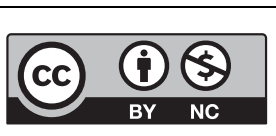

This work is licensed under a Creative Commons Attribution-NonCommercial 4.0 International License. 
Fertility and Sterility 20046 1570-1579. (https://doi.org/10.1016/j. fertnstert.2004.06.040)

17 Nikisch G, Mathe AA, Czernik A, Thiele J, Bohner J, Eap CB, Agren H \& Baumann P. Long-term citalopram administration reduces responsiveness of HPA axis in patients with major depression: relationship with S-citalopram concentrations in plasma and cerebrospinal fluid (CSF) and clinical response. Psychopharmacology 20054 751-760. (https://doi.org/10.1007/s00213-005-0034-3)

18 Jazayeri S, Keshavarz SA, Tehrani-Doost M, Djalali M, Hosseini M, Amini H, Chamari M \& Djazayery A. Effects of eicosapentaenoic acid and fluoxetine on plasma cortisol, serum interleukin-1beta and interleukin- 6 concentrations in patients with major depressive disorder. Psychiatry Research 20101 112-115. (https://doi. org/10.1016/j.psychres.2009.04.013)

19 Zobel AW, Schulze-Rauschenbach S, von Widdern OC, Metten M, Freymann N, Grasmader K, Pfeiffer U, Schnell S, Wagner M \& Maier W. Improvement of working but not declarative memory is correlated with HPA normalization during antidepressant treatment. Journal of Psychiatric Research 20044 377-383. (https://doi. org/10.1016/j.jpsychires.2003.12.002)

20 Topp CW, Ostergaard SD, Sondergaard S \& Bech P. The WHO-5 wellbeing index: a systematic review of the literature. Psychotherapy and Psychosomatics 20153 167-176. (https://doi.org/10.1159/000376585)

21 Bech P, Rasmussen NA, Olsen LR, Noerholm V \& Abildgaard W. The sensitivity and specificity of the Major Depression Inventory, using the Present State Examination as the index of diagnostic validity. Journal of Affective Disorders 2001 2-3 159-164. (https://doi. org/10.1016/S0165-0327(00)00309-8)

22 Lingjaerde O, Ahlfors UG, Bech P, Dencker SJ \& Elgen K. The UKU side effect rating scale. A new comprehensive rating scale for psychotropic drugs and a cross-sectional study of side effects in neuroleptic-treated patients. Acta Psychiatrica Scandinavica 1987334 1-100. (https://doi.org/10.1111/j.1600-0447.1987.tb10566.x)

23 Andresen EM \& Meyers AR. Health-related quality of life outcomes measures. Archives of Physical Medicine and Rehabilitation 200012 (Supplement 2) S30-S45. (https://doi.org/10.1053/apmr.2000.20621)

24 Jedel E, Kowalski J \& Stener-Victorin E. Assessment of health-related quality of life: Swedish version of polycystic ovary syndrome questionnaire. Acta Obstetricia et Gynecologica Scandinavica 200812 1329-1335. (https://doi.org/10.1080/00016340802444762)

25 Ignell C \& Berntorp K. Evaluation of the relationship between capillary and venous plasma glucose concentrations obtained by the HemoCue Glucose 201+ system during an oral glucose tolerance test. Scandinavian Journal of Clinical and Laboratory Investigation 20118 670-675. (https://doi.org/10.3109/00365513.2011.619703)

26 Matthews DR, Hosker JP, Rudenski AS, Naylor BA, Treacher DF $\&$ Turner RC. Homeostasis model assessment: insulin resistance and beta-cell function from fasting plasma glucose and insulin concentrations in man. Diabetologia 19857 412-419. (https://doi. org/10.1007/BF00280883)

27 Matsuda M \& DeFronzo RA. Insulin sensitivity indices obtained from oral glucose tolerance testing: comparison with the euglycemic insulin clamp. Diabetes Care 19999 1462-1470. (https://doi. org/10.2337/diacare.22.9.1462)

28 Phillips DI, Clark PM, Hales CN \& Osmond C. Understanding oral glucose tolerance: comparison of glucose or insulin measurements during the oral glucose tolerance test with specific measurements of insulin resistance and insulin secretion. Diabetic Medicine 19943 286-292. (https://doi.org/10.1111/j.1464-5491.1994.tb00273.x)

29 Knorr U, Vinberg M, Gether U, Winkel P, Gluud C, Wetterslev J \& Kessing LV. The effect of escitalopram versus placebo on perceived stress and salivary cortisol in healthy first-degree relatives of patients with depression-A randomised trial. Psychiatry Research 2012 2-3 354-360. (https://doi.org/10.1016/j.psychres.2012.05.015)
30 Bschor T, Ising M, Erbe S, Winkelmann P, Ritter D, Uhr M \& Lewitzka U. Impact of citalopram on the HPA system. A study of the combined DEX/CRH test in 30 unipolar depressed patients. Journal of Psychiatric Research 20121 111-117. (https://doi.org/10.1016/j. jpsychires.2011.09.020)

31 Sarubin N, Nothdurfter C, Schmotz C, Wimmer AM, Trummer J, Lieb M, Uhr M, Baghai TC, Wetter TC, Buhner M, et al. Impact on cortisol and antidepressant efficacy of quetiapine and escitalopram in depression. Psychoneuroendocrinology 201439 141-151. (https://doi. org/10.1016/j.psyneuen.2013.10.008)

32 Bjorntorp P \& Rosmond R. Obesity and cortisol. Nutrition 200010 924-936. (https://doi.org/10.1016/S0899-9007(00)00422-6)

33 Knorr U, Vinberg M, Hansen A, Klose M, Feldt-Rasmussen U, Hilsted L, Hasselstrom J, Gether U, Winkel P, Gluud C, et al. Escitalopram and neuroendocrine response in healthy first-degree relatives to depressed patients--a randomized placebo-controlled trial. PLOS ONE 20116 e21224. (https://doi.org/10.1371/journal. pone.0021224)

34 Hemmingsson E. A new model of the role of psychological and emotional distress in promoting obesity: conceptual review with implications for treatment and prevention. Obesity Reviews 20149 769-779. (https://doi.org/10.1111/obr.12197)

35 Beyazyuz M, Albayrak Y, Egilmez OB, Albayrak N \& Beyazyuz E. Relationship between SSRIs and metabolic syndrome abnormalities in patients with generalized anxiety disorder: a prospective study. Psychiatry Investigation 20132 148-154. (https://doi.org/10.4306/ pi.2013.10.2.148)

36 Raeder MB, Bjelland I, Emil VS \& Steen VM. Obesity, dyslipidemia, and diabetes with selective serotonin reuptake inhibitors: the Hordaland Health Study. Journal of Clinical Psychiatry 200612 1974-1982. (https://doi.org/10.4088/JCP.v67n1219)

37 Olguner Eker O, Ozsoy S, Eker B \& Dogan H. Metabolic effects of antidepressant treatment. Nöro Psikiyatri Arşivi 20171 49-56. (https://doi.org/10.5152/npa.2016.12373)

38 Calarge CA, Mills JA, Janz KF, Burns TL, Coryell WH \& Zemel BS. Body composition in adolescents during treatment with selective serotonin reuptake inhibitors. Pediatrics 20171 e20163943. (https:// doi.org/10.1542/peds.2016-3943)

39 Nicolau J, Rivera R, Frances C, Chacartegui B \& Masmiquel L. Treatment of depression in type 2 diabetic patients: effects on depressive symptoms, quality of life and metabolic control. Diabetes Research and Clinical Practice 20132 148-152. (https://doi. org/10.1016/j.diabres.2013.05.009)

40 Kamarck TW, Muldoon MF, Manuck SB, Haskett RF, Cheong J, Flory JD \& Vella E. Citalopram improves metabolic risk factors among high hostile adults: results of a placebo-controlled intervention. Psychoneuroendocrinology 20117 1070-1079. (https:// doi.org/10.1016/j.psyneuen.2011.01.005)

41 Uher R, Farmer A, Henigsberg N, Rietschel M, Mors O, Maier W, Kozel D, Hauser J, Souery D, Placentino A, et al. Adverse reactions to antidepressants. British Journal of Psychiatry 20093 202-210. (https:// doi.org/10.1192/bjp.bp.108.061960)

42 Knorr UB. The effect of selective serotonin reuptake inhibitors in healthy first-degree relatives of patients with major depressive disorder - an experimental medicine blinded controlled trial. Danish Medical Journal 20124 B4426.

43 Jakobsen JC, Katakam KK, Schou A, Hellmuth SG, Stallknecht SE, Leth-Moller K, Iversen M, Banke MB, Petersen IJ, Klingenberg SL, et al. Selective serotonin reuptake inhibitors versus placebo in patients with major depressive disorder. A systematic review with metaanalysis and Trial Sequential Analysis. BMC Psychiatry 2017158. (https://doi.org/10.1186/s12888-016-1173-2)

44 Hieronymus F, Lisinski A, Naslund J \& Eriksson E. Multiple possible inaccuracies cast doubt on a recent report suggesting selective http://www.endocrineconnections.org https://doi.org/10.1530/EC-18-0077
() 2018 The authors Published by Bioscientifica Ltd

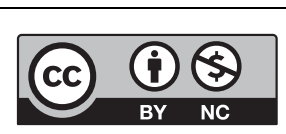

This work is licensed under a Creative Commons Attribution-NonCommercial 4.0 International License. 
serotonin reuptake inhibitors to be toxic and ineffective. Acta Neuropsychiatrica 2017 1-7. (https://doi.org/10.1017/neu.2017.23)

45 Deuschle M. Effects of antidepressants on glucose metabolism and diabetes mellitus type 2 in adults. Current Opinion in Psychiatry 2013 1 60-65. (https://doi.org/10.1097/YCO.0b013e32835a4206)

46 Fjukstad KK, Engum A, Lydersen S, Dieset I, Steen NE,

Andreassen OA \& Spigset O. Metabolic abnormalities related

to treatment with selective serotonin reuptake inhibitors in patients with schizophrenia or bipolar disorder. Journal of Clinical Psychopharmacology 20166 615-620. (https://doi.org/10.1097/ JCP.0000000000000582)

47 Flechtner-Mors M, Jenkinson CP, Alt A, Adler G \& Ditschuneit HH. Metabolism in adipose tissue in response to citalopram and trimipramine treatment - an in situ microdialysis study. Journal of Psychiatric Research 20087 578-586. (https://doi.org/10.1016/j. jpsychires.2007.06.003)

Received in final form 16 February 2018

Accepted 22 February 2018

Accepted Preprint published online 22 February 2018 http://www.endocrineconnections.org https://doi.org/10.1530/EC-18-0077
() 2018 The authors Published by Bioscientifica Ltd

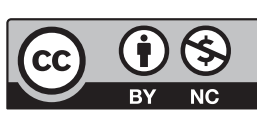

This work is licensed under a Creative Commons Attribution-NonCommercial 4.0 International License. 